\title{
Covid-19: What do we know so far about a vaccine?
}

\author{
Elisabeth Mahase
}

The BMJ

The World Health Organization has announced that 83 potential covid-19 candidate vaccines are being assessed (as at 23 April), including seven that have now been approved for human testing through clinical trials. ${ }^{1}$ The $B M J$ looks at what we know so far.

\section{What do we know about the seven approved candidates?}

Of the seven, three are being tested in Beijing. The vaccine company CanSino Biological, in collaboration with the Beijing Institute of Biotechnology, has the only vaccine in a phase II trial. $^{2}$ The vaccine, which uses an adenovirus vector, is set to be tested in 375 healthy adults, with 125 people in the control group, and will look at adverse reactions within 14 days and at levels of covid-19 neutralising antibodies and of antibodies against the coronavirus spike protein at day 28. Participants will be followed for up to six months. However, while the move to phase II is a good sign, the results of the phase I trial, which looked at adverse reactions seven days after injection, have not been made public.

Sinovac, another Beijing based company, is currently testing its inactivated-virus covid-19 vaccine (PiCoVacc) in a randomised, double blinded, placebo controlled phase I trial involving 144 adults. $^{3}$ The company is planning to test the vaccine on another 600 people during the phase II trial. A preprint concerning the vaccine's effectiveness in mice, rats, and non-human primates found that it conferred " complete protection" against SARS-CoV-2 strains circulating worldwide. ${ }^{4}$ A third candidate, from the Beijing Institute of Biological Products and the Wuhan Institute of Biological Products, is also being evaluated, but little information about this vaccine is available. ${ }^{5}$

In the UK, researchers at the University of Oxford are testing their ChAdOx1 nCoV-19 vaccine, which uses an adenovirus vaccine vector and the SARS-CoV-2 spike protein, on 1102 healthy volunteers, with the MenACWY vaccine (licensed for groups $\mathrm{A}, \mathrm{C}, \mathrm{W}$, and $\mathrm{Y}$ meningococcus) as a control. They chose the MenACWY vaccine as a control instead of a saline solution because they expect to see minor side effects such as sore arm, headache, and fever in the covid-19 vaccine group that would not develop in a saline group, they said.

Meanwhile in the US, Inovio Pharmaceuticals, which is based in Pennsylvania, began testing its DNA platform vaccine in April. Chief executive officer Joseph Kim has told CNBC that he thinks it would be possible to meet a 12 to 18 months timeline for a covid-19 vaccine. "It's possible, especially if you have a platform that's shown to be safe and if you have tested similar approaches before against other pathogens, like we have," Kim said.

Another US company, Moderna, has developed a vaccine called mRNA-1273 with the National Institute of Allergy and Infectious Diseases. The first patients were injected in March, and the trial to examine the vaccine's safety is now being expanded to include 60 adults. The vaccine, which uses an RNA platform, is being given in two doses, with the second jab 28 days after the first. If the trial is successful, the vaccine will move to phase II, where its effectiveness against covid-19 will be tested.

A seventh trial has been approved but is yet to start. ${ }^{7}$ BNT162 is a vaccine programme being developed by the German biotech company BioNTech and the drug company Pfizer. It involves four potential vaccines set to be initially tested in Germany on 200 healthy participants, although the companies plan to include people with a higher risk for severe covid-19 at the second stage of testing. The four vaccine candidates each represent different mRNA formats and target antigens. The companies are also collaborating with the Chinese drug company Fosun Pharma to conduct trials in China and are planning trials in the US (pending regulatory approval).

\section{How difficult is it to create a covid-19 vaccine?}

Robin Shattock, who is leading a covid-19 vaccine trial set to begin in June at Imperial College London, said that developing a vaccine should be relatively easy because, unlike influenza and HIV, the covid-19 virus seemed to be relatively stable.

Speaking on the BBC's Today news programme on 22 April, $^{8}$ he said, "We are very confident that some vaccines will come through and work. There are so many teams working on different approaches, and this virus is not as difficult a target as some of the things we have seen before. So I think scientifically there is a very high chance of success of getting a vaccine."

\section{How long does it usually take to develop a vaccine?}

Vaccine development is a lengthy process that normally takes more than 10 years and costs hundreds of millions of pounds. Clinical trials requiring many years of testing in thousands of people normally begin after around two to five years of initial research into the immune response and then another two years of preclinical trials involving animal testing. If the vaccine is found to be safe and effective, it then must pass the regulatory 
requirements and gain approval. Even once this is completed, the process to manufacture and deliver a vaccine is expensive and complex, requiring specialist, highly regulated facilities.

In the current crisis, a new 12 to 18 month timeframe has been proposed, with teams around the world working with increasing speed to find an effective candidate. Huge sums of money are needed to fund a wide variety of candidates and approaches.

\section{What happens if a successful vaccine is found?}

Wellcome has emphasised that for a vaccine to be rolled out worldwide, requiring billions of doses, global manufacturing capacity must be built. To do this, the foundation said that new manufacturing sites needed to be built before clinical trials were completed to ensure that production could begin as soon as a vaccine was approved. Sites should be distributed around the world to ensure equitable distribution.

\section{Are countries collaborating?}

WHO has brought together world leaders and health partners, including those from the private sector, in an initiative aimed at accelerating the development and production of new covid-19 vaccines, tests, and treatments, and to enable equal access across the world. ${ }^{9}$

At a virtual launch on 24 April the heads of state of France, South Africa, Germany, Vietnam, Costa Rica, Italy, Rwanda, Norway, Spain, Malaysia, and the UK (represented by the first secretary of state, Dominic Raab, because of the prime minister's illness) were joined by the president of the European Commission, the Bill and Melinda Gates Foundation, the Coalition for Epidemic Preparedness Innovations (CEPI), GAVI (the Vaccine Alliance), and many other leading organisations.

The US was notably absent after President Donald Trump announced that the US would freeze funding to the WHO pending an investigation into its handling of the covid-19 pandemic. $^{10}$

WHO's director general, Tedros Adhanom Ghebreyesus, said, "Our shared commitment is to ensure all people have access to all the tools to prevent, detect, treat, and defeat covid-19. No country and no organisation can do this alone."

\section{Could a vaccine end the pandemic?}

WHO has repeatedly warned countries against relying on a vaccine to end the current situation. Speaking at a briefing on 16 April, Catherine Smallwood, senior emergency officer at WHO Europe, said, "We don't know when a vaccine will be available for use in our populations, and what we don't want to do is take action now based on the situation now. We need to think of ourselves in a position of a new normal until such a time that a vaccine might become available to us."11

Ohid Yaqub, senior lecturer at the University of Sussex's science policy research unit, also warned that "there is a long history of over-optimistic vaccine predictions" and that even if a vaccine became available it was "too early even to speculate whether it will have high efficacy or low efficacy."

He added, "I therefore think public policy attention should continue to focus on testing and on healthcare system capacity, and it should focus on lockdown and managing the social costs of (partial) lockdown for as long as possible."

DRAFT landscape of COVID-19 candidate vaccines - 23 April 2020. WHO. https://www. who.int/blueprint/priority-diseases/key-action/draft-landscape-COVID-19-candidatevaccines-23-April-2020.pdf

2 https://clinicaltrials.gov/ct2/show/NCT04341389.

$3 \mathrm{https} / / / \mathrm{clinicaltrials}$.gov/ct2/show/NCT04352608?term=Sinovac\&cntry=CN\&draw=2.

4 https://www.biorxiv.org/content/10.1101/2020.04.17.046375v1.full.pdf.

5 http://www.chictr.org.cn/showprojen.aspx?proj=52227.

6 Inovio Pharmaceuticals expects to finish recruiting coronavirus vaccine volunteers by the end of April, CEO says. CNBC, 2020. https://www.cnbc.com/2020/04/23/inovio-plans-tofinish-recruiting-coronavirus-vaccine-volunteers-in-april.html.

7 https://www.who.int/emergencies/diseases/novel-coronavirus-2019/global-research-onnovel-coronavirus-2019-ncov/solidarity-trial-accelerating-a-safe-and-effective-covid-19vaccine.

$8 \mathrm{https}: / /$ www.bbc.co.uk/sounds/play/p08b4l6g.

9 https://www.reuters.com/article/us-health-coronavirus-who/world-leaders-to-launch-whocovid-19-plan-but-u-s-wont-take-part-idUSKCN2261M7

10 Mahase E. Covid-19: Trump halts WHO funding in move labelled "petulant" and "short sighted". BMJ 2020;369:m1502.32295763

11 https://www.huffingtonpost.co.uk/entry/coronavirus-vaccine-before-lifting-lockdown_uk 5e984573c5b6a92100e30af1.

Published by the BMJ Publishing Group Limited. For permission to use (where not already granted under a licence) please go to http://group.bmj.com/group/rights-licensing/ permissions 